\title{
Kinetics of Transition Metal Ion Catalyzed Oxidation of Some Industrially Important Alcohols using Ammonium Metavanadate in Acidic Medium
}

By Harichandra A Parbat, D V Prabhu \& Anna Pratima Nikalje

Abstract- Oxidation of alcohols has industrial importance as it yields several useful products.

Toxic and costly metal ions like $\mathrm{Os}(\mathrm{VIII}), \mathrm{Cr}(\mathrm{VI})$, and $\mathrm{Ru}$ in different oxidation states are widely used for the oxidation of a variety of organic compounds. We are reporting herein the oxidation of the industrially useful primary alcohols, 2-Chloroethanol, 2-Butoxyethanol and 2Phenoxyethanol using Ammonium metavanadate in acidic medium. Relatively less toxic and cheaper transition metal ions of the first series are effectively used as homogeneous catalysts for the oxidation of the alcohols to the corresponding aldehydes.

2-Chloroethanol is used as a precursor for ethylene oxide and is useful in the manufacture of crop protection chemicals, and pharmaceuticals.2-Butoxyethanol finds use in the making of paints, varnishes and industrial and household cleaners.

Keywords: alcohols, ammonium metavanadate, kinetics, ionic strength, thermodynamic activation parameters, the entropy of activation, transition metal ion catalysts, reaction mechanisms.

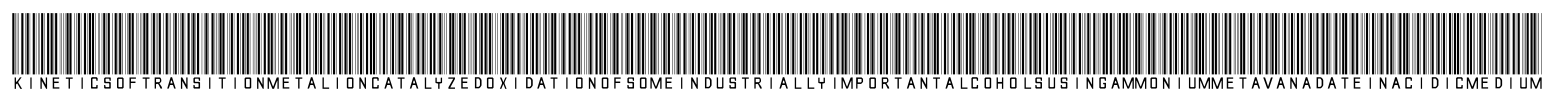

Strictly as per the compliance and regulations of:

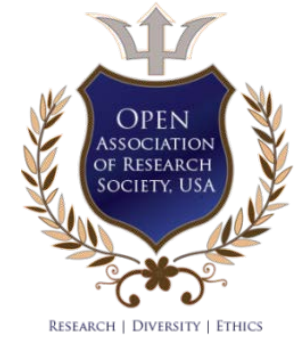

(C) 2019. Harichandra A Parbat, D V Prabhu \& Anna Pratima Nikalje. This is a research/review paper, distributed under the terms of the Creative Commons Attribution-Noncommercial 3.0 Unported License http://creativecommons.org /licenses/by-nc/3.0/), permitting all non commercial use, distribution, and reproduction in any medium, provided the original work is properly cited. 


\title{
Kinetics of Transition Metal lon Catalyzed Oxidation of Some Industrially Important Alcohols using Ammonium Metavanadate in Acidic Medium
}

\author{
Harichandra A Parbat ${ }^{\alpha}$, D V Prabhu ${ }^{\sigma} \&$ Anna Pratima Nikalje ${ }^{\rho}$
}

Abstract- Oxidation of alcohols has industrial importance as it yields several useful products.

Toxic and costly metal ions like Os(VIII), $\mathrm{Cr}(\mathrm{VI})$, and $\mathrm{Ru}$ in different oxidation states are widely used for the oxidation of a variety of organic compounds. We are reporting herein the oxidation of the industrially useful primary alcohols, 2-Chloroethanol, 2-Butoxyethanol and 2-Phenoxyethanol using Ammonium metavanadate in acidic medium. Relatively less toxic and cheaper transition metal ions of the first series are effectively used as homogeneous catalysts for the oxidation of the alcohols to the corresponding aldehydes.

2-Chloroethanol is used as a precursor for ethylene oxide and is useful in the manufacture of crop protection chemicals, and pharmaceuticals.2-Butoxyethanol finds use in the making of paints, varnishes and industrial and household cleaners.

2-Phenoxyethanol serves as a perfume fixative. The oxidation is studied in the presence and absence of transition metal ions under first- order kinetic conditions concerning the inorganic oxidant. The dependence of the oxidation rates of alcohols on concentrations of substrate and oxidant, ionic strength, and temperature is investigated. From the variation of the oxidation rate with temperature, the energy of activation and other thermodynamic activation parameters are evaluated and interpreted in terms of the molecular dynamics of the oxidation process.

The oxidation rates of the alcohols follow the sequence: 2-Chloroethanol > 2-Butoxyethanol > 2Phenoxyethanol, which is explained based on their structural features.

The catalytic effect of the transition metal ions, $\mathrm{Mn}(\mathrm{II})$, $\mathrm{Co}(\mathrm{II})$ and $\mathrm{Ni}$ (II) on the oxidation rates of alcohols is studied in the range $[\mathrm{M}(\mathrm{II})]=2.5$ to $4.5 \times 10^{-4} \mathrm{~mol} \mathrm{dm}^{-3}$, and the sequence of catalytic efficiencies of the metal ions determined. A suitable reaction mechanism is suggested for the oxidation of alcohols using Ammonium metavanadate in acidic medium.

Keywords: alcohols, ammonium metavanadate, kinetics, ionic strength, thermodynamic activation parameters, the entropy of activation, transition metal ion catalysts, reaction mechanisms.

Author a $\sigma \quad \rho$ : Department of Chemistry, Wilson College (aff. University of Mumbai) Mumbai 400007, India.

e-mail:dvprabhu48@gmail.com

\section{INTRODUCTION}

he oxidation of alcohols to carbonyl compounds is extensively reported [1-5]. We have studied the kinetics of oxidation of a variety of alcohols and phenols using organic and inorganic oxidants [6-14]. This paper reports the oxidation of the primary alcohols, 2-Chloroethanol, 2-Butoxyethanol and 2-Phenoxyethanol by Ammonium metavanadate in acidic medium, using transition metal ions as catalysts.

The dependence of oxidation rate on alcohol and oxidant concentrations, ionic strength, and temperature is studied. The thermodynamic activation parameters of the oxidation reaction are evaluated from the variation of oxidation rate with temperature. The sequence of oxidation rates of the alcohols is explained based on their structural features.

Transition metal ions, $\mathrm{Mn}(\mathrm{II}), \mathrm{Co}(\mathrm{II})$, and $\mathrm{Ni}(\mathrm{II})$ are successfully used to catalyze the oxidation of alcohols, and the sequence of their catalytic efficiencies is determined for each substrate. A suitable reaction mechanism is suggested for the oxidation of the primary alcohols under study.

\section{il. Materials and Methods}

The alcohols were obtained from S H Kelkar \& Co., Mumbai, and used after distillation. All other chemicals, solvents, and reagents were of Analytical Grade.

The oxidation of alcohol is studied under firstorder kinetic conditions concerning the inorganic oxidant, ie [oxidant] $<<$ [alc.]. The progress of the reaction is monitored by arresting the reaction using ice and titrating the unreacted oxidant at regular time intervals against standard $\mathrm{Na}_{2} \mathrm{~S}_{2} \mathrm{O}_{3}$ using starch as indicator. The first-order rate constants $(\mathrm{k})$ are obtained from the slopes of the plots of log (unreacted oxidant) versus time. $\mathrm{K}_{2} \mathrm{SO}_{4}$ was used in the range $\mu=0.05-0.25$ $\mathrm{mol} \mathrm{dm^{-3 }}$ to find out the influence of ionic strength on oxidation rates of alcohol. The thermodynamic parameters are evaluated from the Arrhenius plots of $\log \mathrm{k}$ versus $\mathrm{T}^{-1}$. 
A similar procedure is adopted to study the catalytic impact of transition metal ions, $\mathrm{Mn}(\mathrm{II}), \mathrm{Co}(\mathrm{II})$ and $\mathrm{Ni}(\mathrm{II})$ on the oxidation of alcohols.

\section{ili. Results and Discussion}

The primary alcohols, 2-Chloroethanol, 2Butoxyethanol and 2-Phenoxyethanol are oxidized to the corresponding aldehydes in acidic medium. Their oxidation rates increased with [alc.] but decreased with increasing oxidant concentration (Table1, Figure1).

The oxidation rates follow the sequence:

2-Chloroethanol>2-Butoxyethanol > 2-Phenoxyethanol (Table 1, Figure 1)

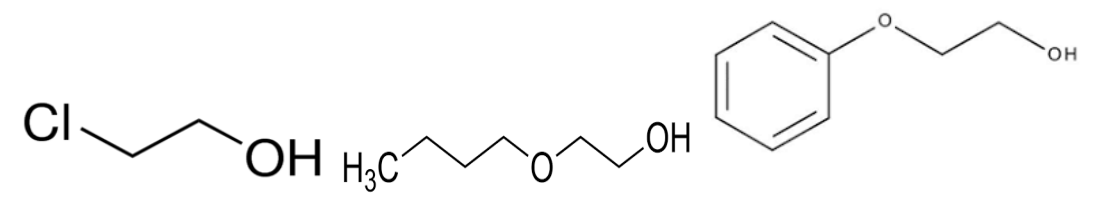

The Chlorine atom in 2-Chloroethanol facilitates the removal of hydrogen atoms making it most susceptible to oxidation.

The influence of ionic strength $(\mu)$ on the oxidation rates of alcohol is studied using $\mathrm{K}_{2} \mathrm{SO}_{4}$ in the range $\mu=0.05-0.25 \mathrm{~mol} \mathrm{dm}^{-3}$ at $313 \mathrm{~K}$ (Table 2). The graphs of log $\mathrm{k}$ versus $\sqrt{ } \mu$ are found to be straight lines parallel to the $\sqrt{ } \mu$ axis, indicating that the rate of oxidation is independent of ionic strength due to the involvement of a nonionic species in the oxidation reaction (Figure 2).

The oxidation of alcohol is carried out in the temperature range $303-313 \mathrm{~K}$, and the thermodynamic activation parameters are determined from the Arrhenius plots of log $k$ versus $T^{-1}$. The negative values of $\Delta S^{*}$ indicate a decrease in entropy due to the formation of a short- lived activated complex, followed by the reorientation of solvent molecules around the activated complex $[15,16]$

2-Chloroethanol $\quad \mathrm{Mn}(\mathrm{II})>\mathrm{Ni}(\mathrm{II})>\mathrm{Co}(\mathrm{II}) \quad$ (Table 4a, Figure 3a)

2-Butoxyethanol $\quad \mathrm{Co}(\mathrm{II})>\mathrm{Ni}(\mathrm{II})>\mathrm{Mn}(\mathrm{II}) \quad$ (Table 4b, Figure $3 \mathrm{~b}$ )

2-Phenoxyethanol $\mathrm{Co}(\mathrm{II})>\mathrm{Ni}(\mathrm{II})>\mathrm{Mn}(\mathrm{II}) \quad$ (Table 4c, Figure 3b)

\section{Conclusions}

1) The alcohols are oxidized as per the sequence, 2-Chloroethanol>2-Botoxyethanol>2-Phenoxyethanol.

2) The oxidation of alcohols is independent of ionic strength in dilute solution by the Bronsted-Bjerrum equation, $\log k=\log k_{0}+1.02 Z_{A} Z_{B} \mu$.

3) There is a decrease in entropy of activation $\Delta S$ * during the oxidation of alcohols.

4) Transition metal ions, $\mathrm{Mn}(\mathrm{II}), \mathrm{Co}(\mathrm{II})$ and $\mathrm{Ni}(\mathrm{II})$ are effectively used to catalyze the oxidation of alcohols.

\section{a) Reaction mechanism of oxidation of alcohols}

In acidic medium, Ammonium metavanadate forms Vanadic acid, which is a strong acid and strong oxidant. For primary alcohol, the oxidation reaction is shown as

$\mathrm{RCH}_{2} \mathrm{OH}+\left(\mathrm{VO}_{3}\right)^{-1}+2 \mathrm{H}^{+}--------\rightarrow \mathrm{RCHO}+(\mathrm{VO})^{+1}+2 \mathrm{H}_{2} \mathrm{O}$

The oxidation product, i.e. aldehyde is identified by 2,4-dinitrophenyl hydrazone test and confirmed by TLC.
Transition metal ions are used to catalyze the oxidation of alcohol to aldehyde using Ammonium metavanadate in acidic medium. $\mathrm{Mn}(\mathrm{II}), \mathrm{Co}(\mathrm{II})$ and $\mathrm{Ni}(\mathrm{II})$ ions are used in the concentration range $[\mathrm{M}(\mathrm{II})]=2.5$ $4.5 \times 10^{-4} \mathrm{~mol} \mathrm{dm}^{-3}$ at $303 \mathrm{~K}$. The rate constants of oxidation of alcohols are determined from the linear plots of log (unreacted oxidant) versus time. In each case, the rate $(k)$ increased with $[M(I I)](T a b l e s 4 a, 4 b$, and 4c, Figures 3a. 3b. and 3c).

The stability order for the complexes of the transition metal ions under study is expected to be $\mathrm{Ni}(\mathrm{II})$ $>\mathrm{Co}(\mathrm{II})>\mathrm{Mn}(\mathrm{II})$ and hence the sequence of their catalytic efficiencies is expected to be $\mathrm{Mn}(\mathrm{II})>\mathrm{Co}(\mathrm{II})$ $>\mathrm{Ni}(\mathrm{II})[17,18]$. However, several discrepancies are observed and reported in literature [19.20]. In our study the sequences of catalytic efficiencies of transition metal ions are as follows:

\section{ACKNOWLEDGEMENT}

Dr. D V Prabhu and Dr. H A Parbat wish to thank Principal Prof Anna Pratima Nikalje, Wilson College, Mumbai for providing all facilities for conducting research and for constant encouragement, help, and support.

\section{References Références Referencias}

1. Collins, J.C. Hess, W.W.1972,Org.Synth.,5,42.

2. Corey, E.J.Suggs, J.W.1975, Tetrahedron Letts., 16,2647 . 
3. Corey, E.J.Boyer, D.L.1978, Tetrahedron Letts., 19, 240.

4. Corey, E.J. Schmidt G.1978, Tetrahedron Letts., 20,399.

5. Deshpande, V. M. Laxmeshwar, N. B. Prabhu, D. V. Proceedings of the International Conference of Chemistry, Indian Chemical Society, Kolkata, India, 1999, B-14.

6. Prabhu, D .V. Tandel, M. A. Parbat, H. A. Gupta Himanshu 2015, Rasayan Journal of Chemistry, 8 , 138.

7. Prabhu, D.V. Rana Chetana 2015, Rasayan Journal of Chemistry, 8, 459.

8. Prabhu, D.V. Rana Chetana 2016, Rasayan Journal of Chemistry, 9, 139.

9. Prabhu, D.V. Rana Chetana 2017, Rasayan Journal of Chemistry, 10, 385. DOI: http://dx.doi.org/ 10.7324/RJC.2017.1021649

10. Prabhu,D.V. Rana Chetana 2018 , Rasayan Journal of Chemistry,11,1084. DOI: http://dx.doi.org/10.31788 /RJC.2018.1131862
11. Parbat H.A. Prabhu, D.V. 2018, Asian Journal of Chemistry, 30, 2581. DOI: http://doi.org/10.14233/ ajchem.2018.21681

12. Parbat, H.A. Prabhu, D.V. 2018, Rasayan Journal of Chemistry,11,1349. DOI: http://dx.doi.org/10.31788 /RJC.2018.1132054

13. Rana Chetana Prabhu, D.V.2019, Research Journal of Chemistry and Environment, 23, 27.

14. Parbat, H.A. Prabhu, D. V., 2018Suppl., Indo American Journal of Pharmaceuticals,5,S46-S51.

15. Eichhorn, G.L. Trachtenberg, I.M. 1954, J. Am. Chem. Soc., 76,5184.

16. Amiss, E.L.1948, Kinetics of chemical change in solution, The Macmillan Co., New York, p.108,110.

17. Irving, H. Williams, R.J.P. 1957, J.Am. Chem.Soc., 3192.

18. Mellor, D.P. Maley, L. 1947, Nature, 158,370. 1948, Nature, 161,436.

19. Williams, R.J.P. 1958, J.Chem.Soc.,8.

20. Prabhu, D.V. Tandel, M.A. Parbat, H.A. 2015, International Journal of Chemistry,4,94.

Table 1: Rate constant data for the oxidation of alcohols by Ammonium metavanadate In $0.1 \mathrm{M} \mathrm{H}_{2} \mathrm{SO}_{4}$ Temp. $=303 \mathrm{~K}$

\begin{tabular}{|c|c|c|c|c|}
\hline & & & ${\mathrm{kx} 10^{4} \mathrm{~s}^{-1}}$ & \\
\hline [alc.] $\times 10^{1}$ & {$\left[\mathrm{NH}_{4} \mathrm{VO}_{3}\right] \times 10^{3}$} & 2-Chloroethanol & 2-Butoxyethanol & 2-Phenoxyethanol \\
\hline $\mathrm{mol} \mathrm{dm}^{-3}$ & $\mathrm{~mol} \mathrm{dm}^{-3}$ & & & 11.80 \\
\hline 0.25 & 5.00 & 14.80 & 12.43 & 13.80 \\
\hline 0.50 & 5.00 & 17.00 & 14.11 & 15.00 \\
\hline 0.63 & 5.00 & 18.42 & 16.39 & 16.60 \\
\hline 0.75 & 5.00 & 20.72 & 17.04 & 17.45 \\
\hline 0.88 & 5.00 & 27.63 & 18.42 & 21.25 \\
\hline 1.00 & 5.00 & 32.24 & 21.41 & 20.95 \\
\hline 1.00 & 2.50 & 34.54 & 29.90 & 16.58 \\
\hline 1.00 & 5.00 & 25.33 & 23.03 & 8.21 \\
\hline 1.00 & 10.00 & 21.18 & 20.72 & 7.44 \\
\hline 1.00 & 15.00 & 18.42 & 16.12 & 5.76 \\
\hline 1.00 & 20.00 & 11.52 & 13.81 & 12.60 \\
\hline 1.00 & 25.00 & 9.90 & & \\
\hline
\end{tabular}

Table 2: Effect of lonic strength on the oxidation rates of alcohols by Ammonium metavanadate in $0.1 \mathrm{M} \mathrm{H}_{2} \mathrm{SO}_{4}$. [alc. $=0.1 \mathrm{M}, \quad\left[\mathrm{NH}_{4} \mathrm{VO}_{3}\right]=2.5 \times 10^{-3} \mathrm{M}$, Temp. $=313 \mathrm{~K}$

\begin{tabular}{|c|c|c|c|c|}
\hline & & & $\mathrm{kx} \mathrm{10}^{4} \mathrm{~s}^{-1}$ & \\
\hline$\mu \mathrm{mol} \mathrm{dm}^{-3}$ & $\sqrt{ } \mu$ & 2-Chloroethanol & 2-Butoxyethanol & 2-Phenoxyethanol \\
\hline 0.00 & 0.00 & 6.82 & 4.54 & 2.24 \\
\hline 0.05 & 0.22 & 6.72 & 4.27 & 2.28 \\
\hline 0.10 & 0.32 & 6.48 & 4.64 & 2.31 \\
\hline 0.15 & 0.39 & 6.53 & 4.50 & 2.21 \\
\hline 0.20 & 0.45 & 6.50 & 4.07 & 2.39 \\
\hline 0.25 & 0.50 & 6.58 & 5.00 & 2.35 \\
\hline
\end{tabular}


Table 3: Thermodynamic activation parameters of the oxidation of alcohols by Ammonium metavanadate in $0.1 \mathrm{M}$ $\mathrm{H}_{2} \mathrm{SO}_{4}$

\begin{tabular}{|c|c|c|c|c|c|c|}
\hline Temp.(K) & $\mathrm{k} \times 10^{4} \mathrm{~s}^{-1}$ & $\mathrm{E} \mathrm{kJ} \mathrm{\textrm {mol } ^ { - 1 }}$ & $\mathrm{K}^{*} \times 10^{16}$ & $\Delta G^{*}$ & $\Delta H^{*}$ & $\Delta \mathrm{S}^{*}$ \\
\hline & & & & $\mathrm{kJ} \mathrm{mol}^{-1}$ & $\mathrm{~kJ} \mathrm{~mol}^{-1}$ & $\mathrm{~kJ} \mathrm{~K}^{-1} \mathrm{~mol}^{-1}$ \\
\hline \multicolumn{7}{|l|}{ 2-Chloroethanol } \\
\hline 303 & 18.42 & 14.24 & 2.92 & 90.13 & 11.72 & -0.2588 \\
\hline 308 & 20.58 & 14.24 & 3.21 & 91.37 & 11.68 & -0.2587 \\
\hline 313 & 27.95 & 14.24 & 4.29 & 92.10 & 11.64 & -0.2571 \\
\hline \multicolumn{7}{|l|}{ 2-Butoxyethanol } \\
\hline 303 & 16.12 & 6.23 & 2.55 & 90.46 & 3.71 & -0.2863 \\
\hline 308 & 17.27 & 6.23 & 2.69 & 91.82 & 3.67 & -0.2862 \\
\hline 313 & 19.34 & 6.23 & 2.97 & 93.06 & 3.62 & -0.2857 \\
\hline \multicolumn{7}{|l|}{ 2-Phenoxyethanol } \\
\hline 303 & 8.24 & 18.08 & 1.31 & 92.15 & 15.56 & -0.2528 \\
\hline 308 & 12.34 & 18.08 & 1.92 & 92.68 & 15.52 & -0.2505 \\
\hline 313 & 13.95 & 18.08 & 2.14 & 93.91 & 15.48 & -0.2506 \\
\hline
\end{tabular}

Table 4: Catalytic effect of transition metal ions on the oxidation of alcohols by Ammonium metavanadate in $0.1 \mathrm{M}$ $\mathrm{H}_{2} \mathrm{SO}_{4}$ [alc.] $=0.1 \mathrm{M},\left[\mathrm{NH}_{4} \mathrm{VO}_{3}\right]=2.5 \times 10^{-3} \mathrm{M}$, Temp. $=303 \mathrm{~K}$

\begin{tabular}{|c|c|c|c|}
\hline $\begin{array}{c}{[\mathrm{M}(\mathrm{II})] \times 10^{4}} \\
\mathrm{~mol} \mathrm{dm}^{-3}\end{array}$ & & $\mathrm{k} \times 10^{4} \mathrm{~s}^{-1}$ & \\
\hline & $\mathrm{Mn}(\mathrm{II})$ & $\mathrm{Co}(\mathrm{II})$ & $\mathrm{Ni}(\mathrm{II})$ \\
\hline \multicolumn{4}{|l|}{$\begin{array}{l}\text { Table 4a. } \\
\text { 2-Chloroethanol }\end{array}$} \\
\hline 0.00 & 4.84 & 4.84 & 4.84 \\
\hline 2.50 & 16.09 & 7.84 & 9.95 \\
\hline 3.50 & 22.22 & 8.24 & 11.75 \\
\hline 4.50 & 27.18 & 9.21 & 14.11 \\
\hline \multicolumn{4}{|l|}{$\begin{array}{l}\text { Table 4b. } \\
\text { 2-Butoxyethanol }\end{array}$} \\
\hline 0.00 & 3.93 & 3.93 & 3.93 \\
\hline 2.50 & 6.63 & 14.96 & 9.90 \\
\hline 3.50 & 7.46 & 16.74 & 13.35 \\
\hline 4.50 & 11.67 & 18.42 & 16.35 \\
\hline \multicolumn{4}{|l|}{$\begin{array}{l}\text { Table 4c. } \\
\text { 2-Phenoxyethanol }\end{array}$} \\
\hline 0.00 & 4.34 & 4.34 & 4.34 \\
\hline 2.50 & 5.76 & 8.70 & 6.91 \\
\hline 3.50 & 8.61 & 14.73 & 9.30 \\
\hline 4.50 & 9.21 & 16.42 & 18.65 \\
\hline
\end{tabular}




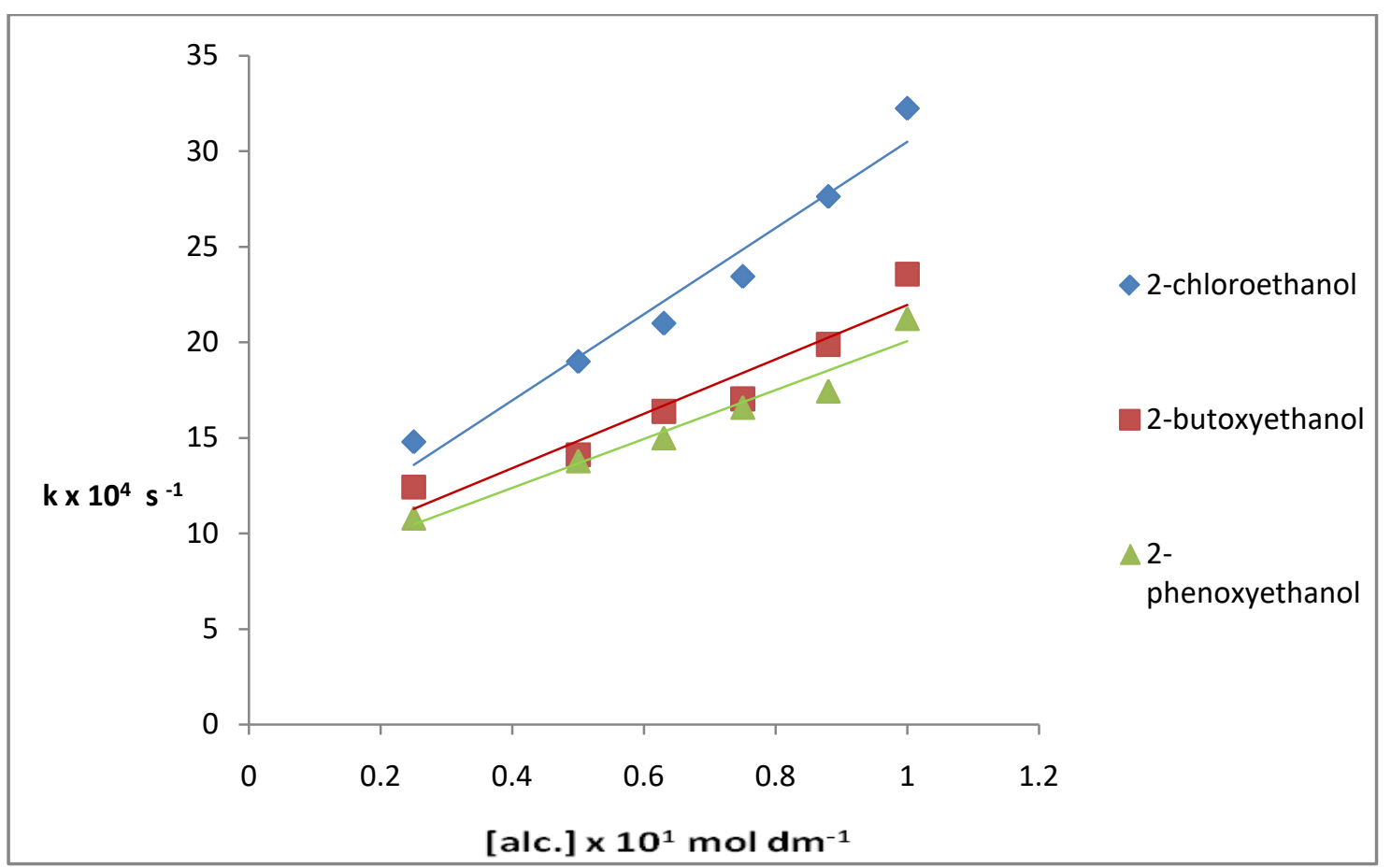

Fig. 1: Variation of rate constant of oxidation of alcohols by Ammonium metavanadate in acidic medium with [alc.]

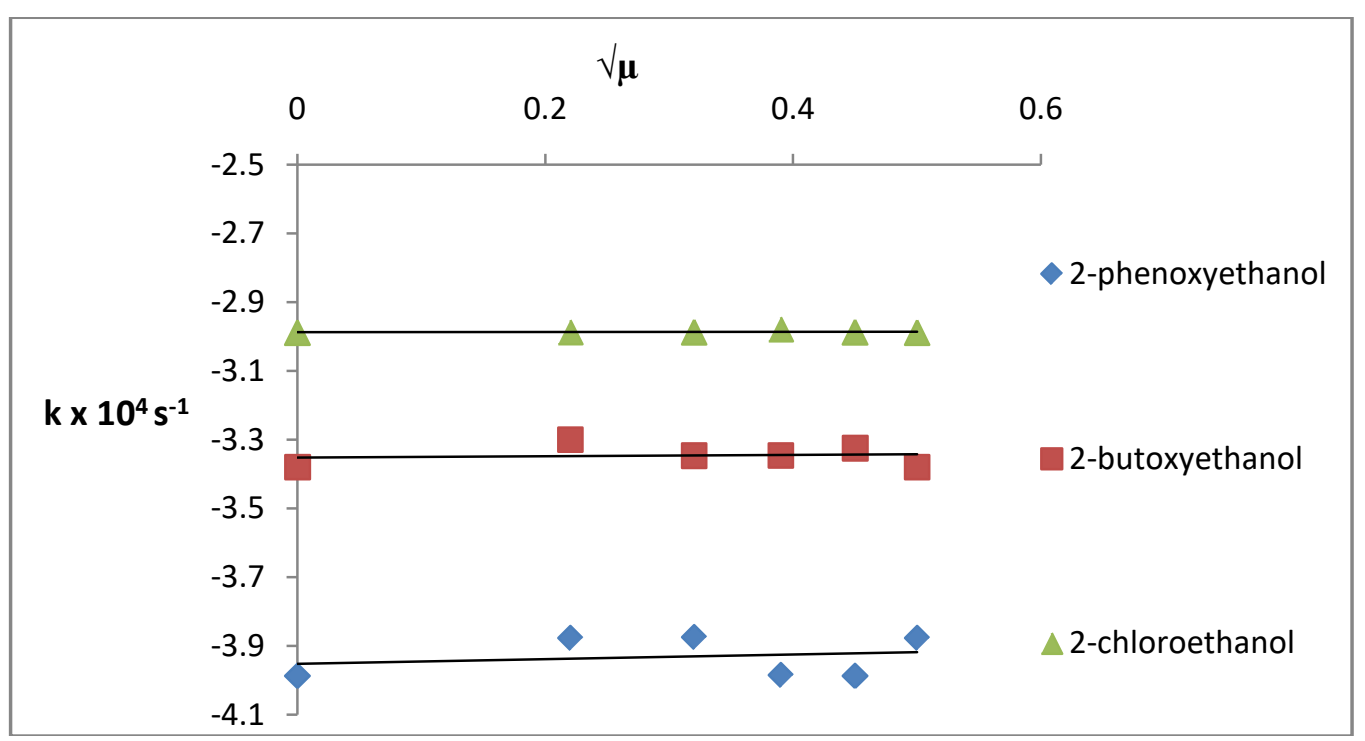

Fig. 2: Effect of ionic strength on the rate constant of oxidation of alcohols by Ammonium metavanadate in acidic medium 


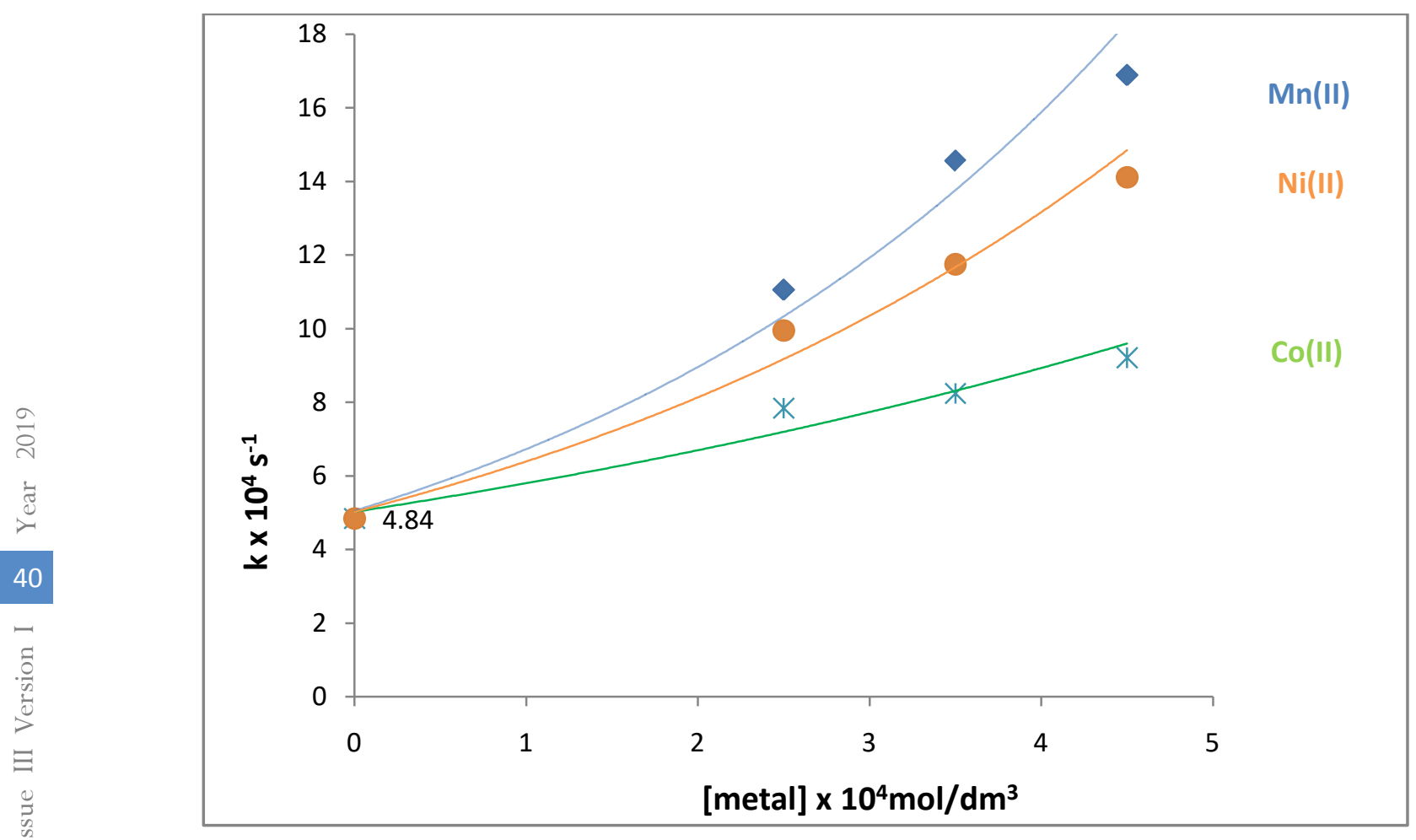

Fig. 3a: Variation of rate constant of transition metal ion catalyzed oxidation of 2-Chloroethanol with [M(II)] Sequence of catalytic efficiencies : $\mathrm{Mn}(\mathrm{II})>\mathrm{Ni}(\mathrm{II})>\mathrm{Co}(\mathrm{II})$

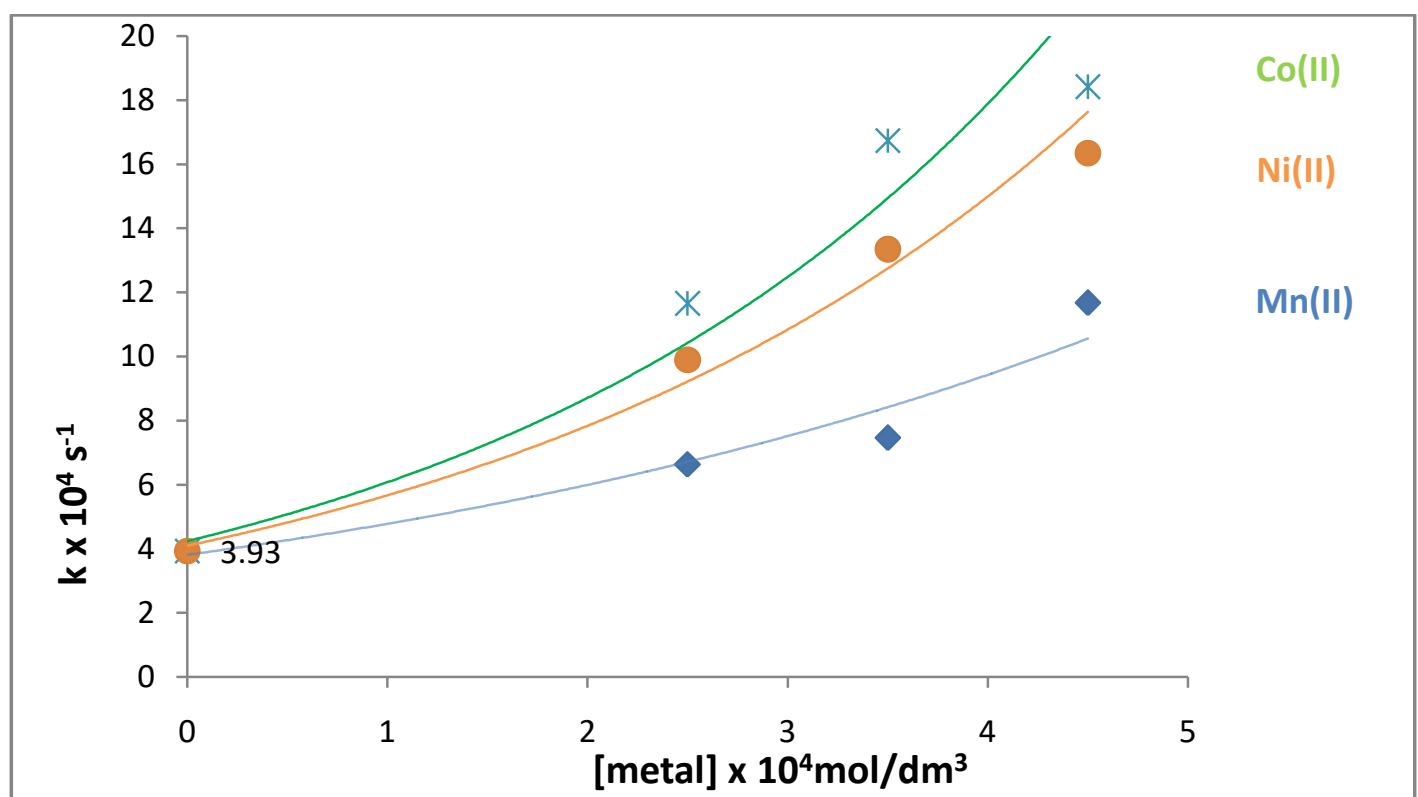

Fig. 3b: Variation of rate constant of transition metal ion catalyzed oxidation of 2-Butoxyethanol with [M(II)] Sequence of catalytic efficiencies: $\mathrm{Co}(\mathrm{II})>\mathrm{Ni}(\mathrm{II})>\mathrm{Mn}(\mathrm{II})$ 


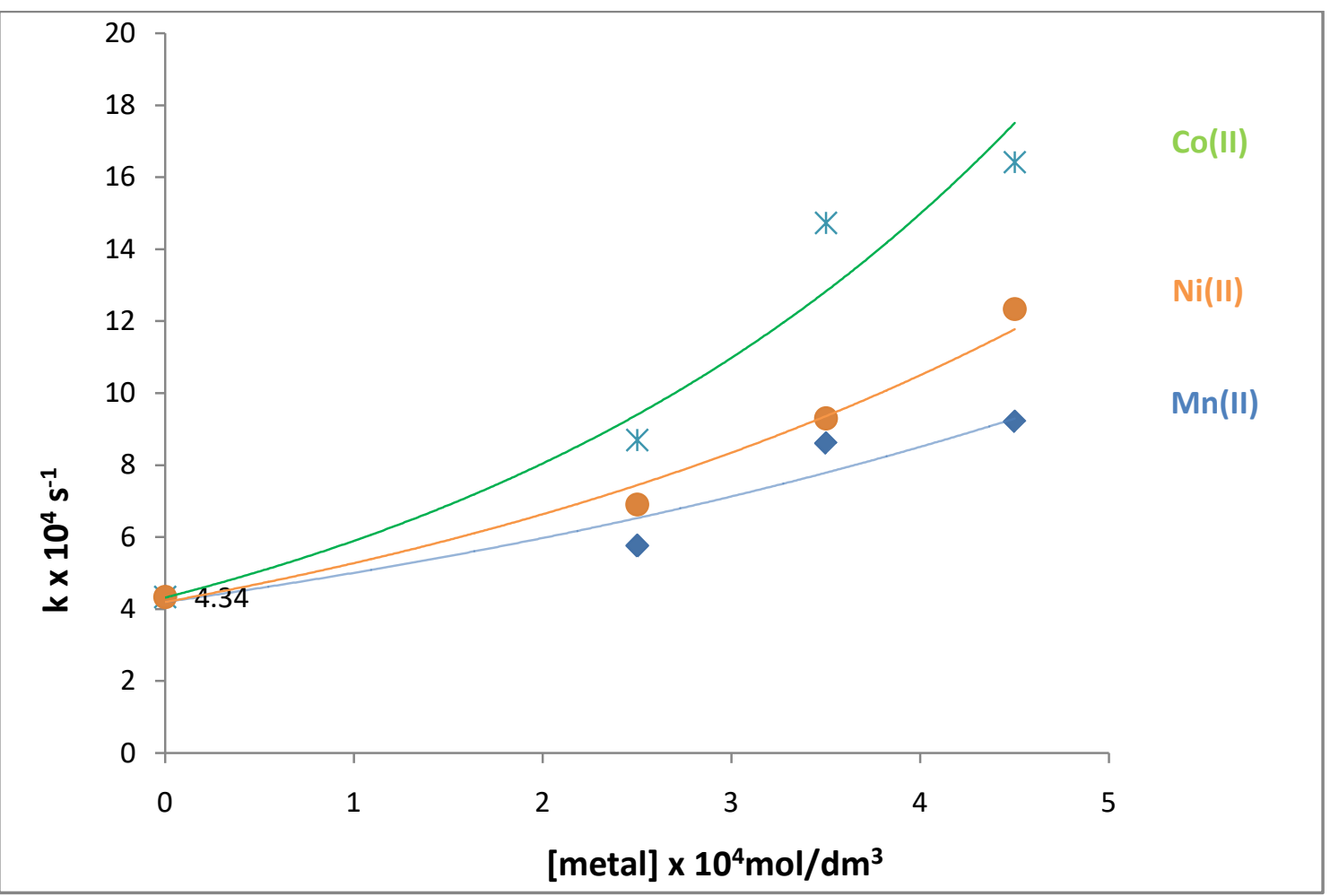

Fig. 3c: Variation of rate constant of transition metal ion catalyzed oxidation of 2-Phenoxyethanol with [M(II)] Sequence of catalytic efficiencies: $\mathrm{Co}(\mathrm{II})>\mathrm{Ni}(\mathrm{II})>\mathrm{Mn}(\mathrm{II})$ 
GLOBAL JOURNALS GUIDELINES HANDBOOK 2019

WWW.GLOBALJOURNALS.ORG 